\title{
IDENTIFIKASI PERUBAHAN POLA CURAH HUJAN MELALUI PERIODOGRAM STANDAR
}

\author{
Gumgum Darmawan \\ Statistika FMIPA UNPAD \\ gumgum@unpad.ac.id \\ Budhi Handoko \\ Statistika FMIPA UNPAD \\ Zulhanif \\ Statistika FMIPA UNPAD
}

\begin{abstract}
Rainfall is time series data that has seasonal pattern, usually period 12. The pattern of rainfall seasonal itself often changes. In this paper, the pattern of rainfall will identify by Periodogram Analysis. We use Time series data from one of city in west Java province. By this analysis, it is proved that the pattern of rainfall has been change. Computation itself, we use macro of Open Source Software R (OSSR).
\end{abstract}

Keywords: rainfall, periodogram, OSSR.

\begin{abstract}
ABSTRAK. Curah hujan merupakan data deret waktu yang telah dikenal mempunyai pola musiman, biasanya mempunyai peride 12 . Pola musiman yang ada pada data curah hujan sering berubah. Pada makalah ini, pola curah hujan akan di identifikasi dengan menggunakan Analisis Peridogram. Data curah hujan yang digunakan dalam penelitian ini adalah data curah hujan di suatu kota di Jawa Barat. Melalui Analisis Periodogram terbukti bahwa pola curah hujan di kota tersebut mengalami perubahan. Proses komputasi sendiri, penulis menggunakan bantuan Macro Open Source Software R
\end{abstract}

Kata Kunci: curah hujan, periodogram, OSSR.

\section{PENDAHULUAN}

Hujan adalah suatu fenomena alam yang sudah dikenal, terutama di daerah yang beriklim tropis. Hujan memerlukan keberadaan lapisan atmosfer tebal agar dapat menemui suhu di atas titik leleh es di dekat dan di atas permukaan Bumi. Di Bumi, hujan adalah proses kondensasi uap air di atmosfer menjadi butir air yang cukup berat untuk jatuh dan biasanya tiba di daratan. Dua proses yang mungkin terjadi bersamaan dapat mendorong udara semakin jenuh menjelang hujan, yaitu pendinginan udara atau penambahan uap air ke udara. 
Prakiraan Presipitasi Kuantitatif (disingkat PPK; QPF dalam bahasa Inggris) adalah perkiraan jumlah presipitasi cair yang terkumpul dalam periode tertentu di suatu daerah. PPK akan diperinci ketika jenis presipitasi terukurkan yang mencapai batas minimal merupakan prakiraan untuk setiap am selama periode sah PPK. Model prakiraan memperlihatkan sensitivitas tertentu terhadap tingkat kelembapan di lapisan pelindung planet, atau di tingkat terendah atmosfer yang menurun seiring ketinggiannya. PPK dapat dibuat dengan dasar prakiraan jumlah kuantitatif atau kemungkinan prakiraan jumlah kualitatif. Teknik prakiraan citra radar memperlihatkan kemampuan yang lebih tinggi daripada prakiraan model dalam 6 hingga 7 jam waktu citra radar. Prakiraan dapat diverifikasi melalui pemakaian pengukur hujan, prakiraan radar cuaca, atau keduanya. Berbagai skor kemampuan dapat ditentukan untuk mengukur nilai prakiraan curah hujan.

Di daerah musim hujan dan kemarau, nutrien tanah tersapu dan erosi meningkat selama musim hujan. Hewan memiliki strategi adaptasi dan bertahan hidup di wilayah basah. Musim kemarau sebelumnya mengakibatkan kelangkaan makanan menjelang musim hujan, karena tanaman panen harus tumbuh terlebih dahulu. Negara-negara berkembang mencatat bahwa penduduknya memiliki fluktuasi berat badan musiman karena kelangkaan makanan sebelum panen pertama yang terjadi pada akhir musim hujan. Hujan dapat ditampung menggunakan tangki air hujan; diolah agar dapat dikonsumsi, non-konsumsi dalam ruang atau irigasi. Hujan berlebihan dalam waktu singkat dapat menyebabkan banjir bandang.

Penelitian tentang data tingkat curah hujan telah dilakukan oleh banyak peneliti, seperti Widya,F (2016), meramalkan anomali curah hujan kota sumedang menggunakan Metode Pemodelan fungsi Transfer dan Metode Singular Spectrum Analysis. Julinda, V(2015), Metode peramalan Multivariate Singular Spectrum Analysis (MSSA) pada kasus curah hujan bulanan kota Semarang. Yuanas,R,O (2015), Perbandingan peramalan curah hujan di wilayah Bandara Juanda Surabaya menggunakan Singular Spectrum Analysis (SSA) dan Seasonal-ARIMA (SARIMA), Darmawan,G;Hendrawati,T Dan Arisanti R (2014), meramalkan 
kejadian banjir dengan meramalkan tingkat curah hujan. Dari keempat penelitian tersebut menunjukan bahwa data musiman merupakan data yang cukup menarik untuk diteliti terutama data tentang curah hujan.

Berdasarkan latar belakang di atas, maka perlu dilakukannya peramalan tentang tingkat curah hujan agar dapat dilakukan persiapan akan terjadinya banjir yang disebabkan oleh hujan yang cukup lebat. Dalam penelitian ini akan di kaji suatu data tingkat curah hujan yang cukup unik, yaitu data tingkat curah hujan di daerah Ciamis. Di daerah ini pola curah hujannya memiliki periode yang berubahubah, berbeda dengan daerah lainnya, sehingga menarik minat peneliti untuk mengkaji perubahan pola curah hujan yang terjadi di daerah ini.

Pengamatan perubahan pola curah hujan tidak cukup dengan melihat secara visual. Diperlukan suatu alat (tools) agar analisis yang dilakukan lebih akurat. Dalam penelitian ini, peneliti membuat suatu prosedur untuk mengidentifikasi musiman Darmawan, G., Mulyani, S. dan Sudartianto (2012), dengan membuat macro $R$ software. Selain mengidentifikasi pola musiman pada penelitian ini dicari dan ditentukan suatu titik yang merupakan structure change dari data history yang tampak dalam pola curah hujan tersebut.

\section{METODE PENELITIAN}

Dalam penelitian ini prosedur yang digunakan dalam proses identifikasi pola tingkat curah hujan mengacu pada Darmawan, G., Mulyani, S. dan Sudartianto (2012).

Tahapan-tahapan untuk melakukan Pengujian musiman dengan periodogram adalah sebagai berikut :

1. Tentukan data yang akan diuji musiman, dalam penelitian ini adalah curah hujan.

2. Karena Persamaan (1), pada dasarnya secara esensi koefisien fourier sama dengan koefisien pada regresi standar maka bila diimplementasikan pada data dapat dituliskan menjadi persamaan fourier sebagai berikut:

$$
Z_{t}=\sum_{k=0}^{[n / 2]}\left(a_{k} \cos \omega_{k} t+b_{k} \sin \omega_{k} t\right),
$$


dengan $\mathrm{k}=0,1, \ldots,[\mathrm{n} / 2]$ dan $\omega_{k}$ merupakan frekuensi fourier yang dapat dihitung dengan rumusan $\omega_{k}=2 \pi . \mathrm{k} / \mathrm{n}$.

3. Hitung $a_{k}$ dan $b_{k}$ dengan rumusan sebagai berikut :

$$
\begin{aligned}
& a_{k}=\left\{\begin{array}{c}
\frac{1}{n} \sum_{t=1}^{n} z_{t} \cos \omega_{k} t, \quad \mathrm{k}=0 \text { dan } \mathrm{k}=\frac{n}{2} \text { jika n genap } \\
\frac{2}{n} \sum_{t=1}^{n} z_{t} \cos \omega_{k} t, \quad \mathrm{k}=1,2, \ldots, \frac{(n-1)}{2}
\end{array}\right. \\
& b_{k}=\frac{2}{n} \sum_{t=1}^{n} z_{t} \sin \omega_{k} t, \quad \mathrm{k}=1,2, \ldots, \frac{(n-1)}{2}
\end{aligned}
$$

4. Hitung nilai ordinat $I\left(\omega_{k}\right)$ dengan rumusan sebagai berikut :

$$
\mathrm{I}\left(\omega_{k}\right)= \begin{cases}n a_{0}^{2} & \mathrm{k}=0 \\ \frac{n}{2}\left(a_{k}^{2}+b_{k}^{2}\right) & \mathrm{k}=1,2, \ldots, \frac{(n-1)}{2}, \\ n a_{k}^{2} & \text { dan } \mathrm{k}=\frac{n}{2} \text { ketika n genap }\end{cases}
$$

5. Uji keberartian terhadap masing - masing frekuensi fourier dengan hipotesis statistik sebagai beikut :

$$
\begin{aligned}
& H_{0}: \alpha=\beta=0 \quad \text { (data tidak dipengaruhi faktor musiman) } \\
& H_{1}: \alpha \neq 0 \text { atau } \beta \neq 0 \text { (data dipengaruhi faktor musiman) }
\end{aligned}
$$

Diuji degan menggunakan statistik uji:

$$
T=\frac{I^{(1)}\left(\omega_{(1)}\right)}{\sum_{k=1}^{[n / 2]} I\left(\omega_{k}\right)}
$$

dengan

$I^{(1)}\left(\omega_{(1)}\right)$ : ordinat maksimum dari periodogram pada frekuensi fourier

$I\left(\omega_{k}\right) \quad$ : nilai ordinat periodogram pada fekuensi fourier $\mathrm{ke}-\mathrm{k}$.

Kriteria uji:

Tolak $H_{0}$ jika T-hitung $>\mathrm{g}_{\alpha}$ dengan $\alpha=$ taraf signifikansi. Nilai $\mathrm{g}_{\alpha}$ dapat dilihat dalam Tabel 1. 
Tabel 1. Nilai Kritis $\alpha=0,05$ untuk rasio nilai Periodogra terbesar

\begin{tabular}{|c|c|c|}
\hline $\mathbf{N}^{*}$ & $\mathrm{~g}_{\alpha}$ ( by exact formula $)$ & $\mathrm{g}_{\alpha}$ (by first term only ) \\
\hline 5 & .68377 & .68377 \\
\hline 10 & .44495 & .44495 \\
\hline 15 & .33462 & .33643 \\
\hline 20 & .27040 & .27046 \\
\hline 25 & .22805 & .22813 \\
\hline 30 & .19784 & .19794 \\
\hline 35 & .17513 & .17525 \\
\hline 40 & .15738 & .15752 \\
\hline 45 & .14310 & .14324 \\
\hline 50 & .13135 & .13149 \\
\hline
\end{tabular}

Diuji dengan statistik uji:

$$
F=\frac{(n-3)\left(a_{k}^{2}+b_{k}^{2}\right)}{2 \sum_{\substack{j=1 \\ j \neq k}}^{[n / 2]}\left(a_{j}^{2}+b_{j}^{2}\right)}
$$

Dengan $\mathrm{j}=1,2, \ldots,(n-1) / 2$ dan $\mathrm{k}=\mathrm{n} / 2$.

Kriteria uji:

Tolak $H_{0}$ jika F-hitung $>$ Ftabel $(2, \mathrm{n}-3 ; \alpha)$ dengan $\alpha=$ taraf signifikansi.

6. Buat tabel periodogram yang diperkenalkan oleh Schuster (1898) untuk mencari komponen periodik (musiman) dalam suatu deret, dengan bentuk tabel sebagai berikut:

Tabel 2. Analisis Periodogram

\begin{tabular}{|c|c|c|c|c|}
\hline $\mathrm{k}$ & Freq $\left(\omega_{k}\right)$ & Periode $(\mathrm{P})$ & $I\left(\omega_{k}\right)$ & $\mathrm{F}$ \\
\hline 1 & $\omega_{1}$ & $P_{1}$ & $I\left(\omega_{1}\right)$ & $f_{1}$ \\
\hline 2 & $\omega_{2}$ & $P_{2}$ & $I\left(\omega_{2}\right)$ & $f_{2}$ \\
\hline
\end{tabular}




\begin{tabular}{|c|c|c|c|c|}
\hline$:$ & $:$ & $:$ & $:$ & $:$ \\
\hline$:$ & $:$ & $:$ & $:$ & $:$ \\
\hline $\mathrm{n} / 2$ & $\omega_{\mathrm{n} / 2}$ & $P_{\mathrm{n} / 2}$ & $I\left(\omega_{n / 2}\right)$ & $f_{\mathrm{n} / 2}$ \\
\hline
\end{tabular}

dengan $P=\frac{2 \pi}{\omega_{k}}$.

7. Berdasarkan tabel periodogram, dapat diketahui hasil pengujian yang signifikan dengan cara membandingkan nilai $\mathrm{F}$ hitung dengan $\mathrm{F}$ tabel yang dapat dilihat pada tabel distribusi $\mathrm{F}$ dengan diketahui $v 1=2$, v2 $=\mathrm{n}-3$ dan $\alpha=$ taraf signifikansi. Jika $H_{0}$ signifikan berarti mengindikasikan bahwa terdapat pola musiman. Pengujian terhadap masing - masing frekuensi fourier ini hanya memberitahukan ada tidaknya pola musiman pada suatu deret namun tidak memberikan informasi dimana letak pola tersebut.

8. Pengujian untuk melihat dimana letak pola musiman tadi digunakan perumusan statistik sebagai berikut :

$$
\begin{array}{ll}
H_{0}: \alpha=\beta=0 & \text { (data tidak dipengaruhi faktor musiman) } \\
H_{1}: \alpha \neq 0 \text { atau } \beta \neq 0 & \text { (dipengaruhi faktor musiman) }
\end{array}
$$

Dan diuji dengan statistik uji yang dapat dilihat pada Persamaan (2) di mana nilai $I^{(1)}\left(\omega_{(1)}\right)$ diperoleh dari rumusan sebagai berikut:

$$
I^{(1)}\left(\omega_{(1)}\right)=\max \left\{I\left(\omega_{k}\right)\right\} .
$$

Kriteria uji bandingkan $\mathrm{T}$ hitung dari Persamaan (2) dengan $\mathrm{g}_{\alpha}$ yang dapat dilihat pada Tabel 1. Nilai $\mathrm{g}_{\alpha}$ pada tabel terdiri atas dua bagian yaitu :

a. $\mathrm{g}_{\alpha}$ by exact formula didapat dengan rumusan sebagai berikut:

$$
P(T>g)=\sum_{j=1}^{m}(-1)^{(j-1)}\left(\begin{array}{c}
N \\
j
\end{array}\right)(1-j g)^{N-1},
$$

dengan $\mathrm{g}>0$ dan $\mathrm{m}$ merupakan integer terbesar kurang dari $1 / \mathrm{g}$. Jadi untuk setiap $\alpha$ tingkat signifikansi tertentu, dapat digunakan Persamaan (9) untuk menemukan nilai kritis $g_{\alpha}$ seperti berikut :

$$
P\left(T>g_{\alpha}\right)=\alpha \text {. }
$$


b. Sedangkan untuk nilai $\mathrm{g}_{\alpha}$ by first term only diperoleh dari pendekatan pada Persamaan (9) sehingga didapat :

$$
P(T>g) \cong N(1-g)^{N-1} .
$$

Hasil $\mathrm{g}_{\alpha}$ by exact result dan by first term only nyatanya hampir sama atau tidak berbeda jauh. Bahkan untuk besar sampel yang kecil, hasilnya sama. Sehingga by first term only disarankan untuk sampel yang lebih besar dan juga alasan kepraktisan.

Setelah membandingkan nilai $\mathrm{T}$ hitung dengan $\mathrm{g}_{\alpha}$, jika hasilnya signifikan ( $H_{0}$ ditolak) maka dapat disimpulkan bahwa deret data mengandung komponen musiman.

9. Membuat macro software $\mathrm{R}$ untuk prosedur diatas agar dapat diimplementasikan untuk data curah hujan yang akan di analisis. Macro R untuk menganalisis pola musiman ada di Darmawan, G., Mulyani, S. dan Sudartianto (2012).

Melakukan pemotongan data di mulai dari $\mathrm{i}=24,36,48, \ldots$ untuk melihat perubahan pola curah hujan.

\section{HASIL DAN PEMBAHASAN}

Pada bagian ini akan dianalisis data curah hujan di suatu tempat di Ciamis. Bulanan selama 132 bulan atau selama 11 tahun. Gambar dari pola tingkat curah hujan dapat dilihat pada Gambar.

\subsection{Identifikasi Awal}

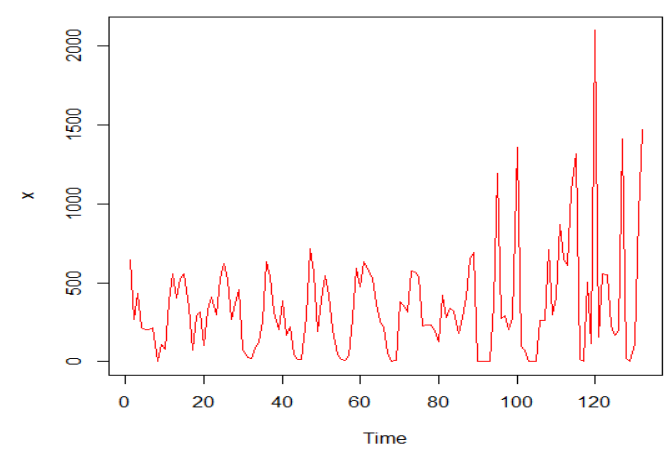

Gambar. Pola Data Curah hujan di Daerah Cimulu (Ciamis) 
Berdasarkan gambar diatas tampak pola hujan secara menyeluruh (global) bersifat sinusoidal, ini menunjukan bahwa pola curah hujan bersifat musiman. Dari gambar diatas, pola musiman yang terbentuk mempunyai dua periode yang berbeda. Dari data pertama sampai data sekitar 84 bulan mempunyai pola yang homogen yaitu sebesar periode 12, tapi data setelah itu sampai akhir periodenya berubah.

\subsection{Penentuan Pola Dan Periode Secara kumulatif (A)}

Langkah pada bagian 2 (Tahapan - tahapan untuk melakukan Pengujian musiman dengan periodogram) di buat macro R-nya tersedia di Darmawan, G., Mulyani, S. dan Sudartianto (2012). Pada bagian A no 1, 24 data pertama di eksekusi menghasilkan periode 12, begitu juga untuk 36 data pertama,48 data pertama dan data secara keseluruhan (no.8). Semuanya menghasilkan periode musiman sebesar $\mathrm{L}=12$.

Pada bagian ini akan di coba kekonsistenan pola curah hujan dimulai dari 1-2L,1-3L,1-4L,...1-N. Dari hasil seluruh pengujian ternyata periode dari seluruh potongan data diatas mempunyai periode $\mathrm{L}=12$ (lihat Tabel 3, Kolom A).

\subsection{Penentuan Pola Dan Periode Secara Terpancung Di awal (B)}

Pada bagian ini dicoba dengan prosedur pada bagian 2, akan tetapi datanya dimulai dari $j$ sampai $N$-j. Tampak terlihat hasil pengujian (lihat Tabel 3, Kolom B), dari $j=48,60,72,84$ sampai $N$ data tidak mempunyai pola musiman. Untuk $j=$ $96-\mathrm{N}$ data mempunyai pola musiman dengan periode 4 , sedangkan untuk $j=108$ $\mathrm{N}$ data mempunyai periode 6 . Hal ini menunjukan bahwa ada ketidak konsistenan baik dari pola curah hujan maupun periode curah hujan itu sendiri.

Tabel 3. Hasil Pengujian Pola dan Periode Musiman

\begin{tabular}{|c|c|c|c|}
\hline No & Batas & \multicolumn{2}{|c|}{ PERIODE } \\
\cline { 3 - 4 } & $(j)$ & $\mathrm{A}$ & $\mathrm{B}$ \\
\hline 1 & 24 & 12 & 12 \\
\hline 2 & 36 & 12 & 12 \\
\hline
\end{tabular}




\begin{tabular}{|c|c|c|c|}
\hline 3 & 48 & 12 & - \\
\hline 4 & 60 & 12 & - \\
\hline 5 & 72 & 12 & - \\
\hline 6 & 84 & 12 & - \\
\hline 7 & 96 & 12 & 4 \\
\hline 8 & 108 & 12 & 6 \\
\hline
\end{tabular}

Nilai-nilai batas $(j)$ ditentukan berdasarkan periode musiman terbesar ( $\mathrm{L}=12$ ) dan kelipatannya yaitu 24,36 dan seterusnya. Jika pola curah hujan di Cimulu Ciamis tersebut konsisten, maka kolom A dan B akan bernilai sama, artinya data dipotong di bagian manapun Periodenya (L) akan bernilai sama. Dua baris terakhir yaitu, $j=96$ dan 108, periodenya adalah 4 dan 6, ini menunjukan bahwa periode musiman telah berubah yang asalnya 12 bulan menjadi 4 dan 6 bulan, artinya intensitas curah hujan semakin tinggi pertahunnya.

\section{KESIMPULAN DAN SARAN}

Berdasarkan hasil analisis di atas, data curah hujan di daerah Cimulu mempunyai pola curah hujan yang spurious. Hal ini yang menyebabkan pemodelan pada data curah hujan akan semakin sulit dimodelkan. Bagi peneliti yang mempunyai data curah hujan yang lengkap 11 tahun, akan menjustifikasi bahwa data mempunyai pola curah hujan dengan periode 12 , tapi bagi peneliti yang mempunyai data curah hujan Cimulu dari $j-N$, dimana $j=48,60,72,84$, akan menjustifikasi bahwa data curah hujan di daerah Cimulu tidak mempunyai pola musiman.

Peneliti yang mempunyai data curah hujan dari $j$ - $N$ dengan $j=96$ akan mengidentifikasi bahwa data curah hujan akan mempunyai pola musiman dengan periode 4 , sedangkan peneliti lain yang mempunyai data curah hujan dari $j-N$ dengan $j=108$ akan mengidentifikasi bahwa data curah hujan akan mempunyai pola musiman dengan periode 6 .

Kesimpulan dari hasil analisis diatas menunjukan bahwa telah terjadi perubahan pola curah hujan dan terjadi perubahan periode curah hujan dari data histori diatas. Sarannya, diperlukan suatu model yang kompleks untuk memodelkan data seperti ini. 
Saran dalam penelitian ini, perlu dikaji data curah hujan di wilayah terdekatnya. Apakah ini terjadi hanya di Cimulu atau terjadi juga di wilayah yang lain sekitar Ciamis. Selain itu perlu juga, diperiksa faktor apa yang bias menyebabkan terjadinya inskonsistensi pola dan periode curah hujan di Cimulu.

\section{DAFTAR PUSTAKA}

Darmawan, G., Mulyani, S. dan Sudartianto, Pengujian Pola Musiman Pada Data Deret Waktu Dengan Menggunakan Regresi Spektral, Universitas Padjadjaran, Jatinangor, 2012.

Darmawan, G., Hendrawati, T, dan Arisanti, R, Pemilihan Model Terbaik Untuk Meramalkan Kejadian Banjir di Kota Bandung Dan Sekitarnya, Fakultas Matematika Dan Ilmu Pengetahuan Alam UNPAD, 2014.

Julinda, V., Metode Peramalan Multivariate Singular Spectrum Analysis (MSSA) Pada kasus curah hujan bulanan Kota Semarang, Skripsi, Departemen Statistika FMIPA UNPAD, 2015.

Yuanas, R. O., Perbandingan Peramalan Curah Hujan Di Wilayah Bandara Juanda Surabaya Menggunakan Singular Spectrum Analysis (SSA) dan Seasonal-ARIMA (SARIMA), Skripsi, Departemen Statistika FMIPA UNPAD, 2015.

Wei William, W. S., Time Series Analysis Univariate and Multivariate Methods, Addison-Wesley Publishing Company, Inc., United States of America, 2006.

Widya, F., Perbandingan Peramalan Anomali Curah Hujan Kota Sumedang Menggunakan Metode Pemodelan Fungsi Transfer dan Metode Singular Spectrum Analysis (SSA), Skripsi, Departemen Statistika FMIPA UNPAD, 2016. 